\title{
Knowledge Society Network: Toward a Dynamic, Sustained Network for Building Knowledge
}

\section{Le Knowledge Society Network : vers un réseau dynamique et durable pour la coélaboration de connaissances}

Huang-Yao Hong, Marlene Scardamalia, and Jianwei Zhang

Authors
Huang-Yao Hong, Assistant Professor, National Chengchi University, Taiwan. Correspondence
regarding this article can be sent to hyhong@nccu.edu.tw
Marlene Scardamalia, Presidents' Chair in Education and Knowledge Technologies and Director,
Institute for Knowledge Innovation and Technology, OISE, University of Toronto
Jianwei Zhang, Assistant Professor, University at Albany, USA

\section{Abstract}

The Knowledge Society Network (KSN) "takes advantage of new knowledge media to maximize and democratize society's knowledge-creating capacity" (www.ikit.org/KSN). This article synthesizes the principles and designs of this network which were initiated over 15 years ago, and presents an exploratory study of interactions in the KSN over four years, elaborating different network structures and the potential of each for knowledge advancement. Four major sub-network structures for participant and idea interaction are described, as reflected in social network analysis of discourse in the KSN. Strengths and weaknesses of work within each sub-network were identified with suggestions for creating a more dynamic, sustained network for knowledge advancement.

\section{Résumé}

Le Knowledge Society Network (KSN) tire avantage des nouveaux médias pour maximiser et démocratiser la capacité de création de connaissances au sein de la société. L'article résume les principes et le fonctionnement du réseau, lancé il y a plus de 15 ans, et présente une étude sur les interactions au sein du KSN sur une période de quatre ans, expliquant diverses structures de réseau et le potentiel de chacune pour le développement des connaissances. Quatre importantes structures de sous-réseaux pour la participation et l'interaction dans des échanges d'idées sont décrites; ces structures sont reflétées dans une analyse du discours du réseau social KSN. Les forces et les faiblesses de fonctionnement de chaque sous-réseau ont été identifiées, et des conseils sont donnés afin de créer un réseau plus dynamique et durable en matière de développement des connaissances. 


\section{Introduction}

Society is being transformed into a "knowledge society" (Drucker, 1968). Governments everywhere are striving to increase their capacity to create new knowledge and address what Homer-Dixon (2000) has termed the "ingenuity gap" and the corresponding, growing need for new knowledge to deal with emerging problems and opportunities. The advances and ubiquity of communication and Internet technology provide new forms of connectivity for dispersed knowledge workers, transforming the nature and process of knowledge work. As described in a UNESCO (2005) report titled Towards Knowledge Societies, "The magnitude of technological change, which over recent decades has affected the means of knowledge creation, transmission and processing, have brought a number of experts to hypothesize that we stand on the threshold of a new era of knowledge" (p.47).

To develop and spread Knowledge Building innovations a Knowledge Society Network (KSN) has been established that is open to members of the broad international community engaged in knowledge building research and development including scholars, teachers, engineers, students and policy makers. It represents a design experiment that takes advantage of new knowledge media to maximize society's knowledge building capacity (Scardamalia, 2003a; Scardamalia, Hong, \& Zhang, 2006). In this paper, we provide a brief overview of the KSN, elaborate its principles and designs, identify four types of network structures, and present an exploratory study of evolving network interactions over four years.

\section{An Overview of the Knowledge Society Network (KSN)}

The core concept that has unified and given direction to the KSN is Knowledge Building: "the production and continual improvement of ideas of value to a community, through means that increase the likelihood that what the community accomplishes will be greater than the sum of individual contributions" (Scardamalia \& Bereiter, 2003, p. 1371). Knowledge building is synonymous with knowledge creation and "goes on throughout a knowledge society and is not limited to education" (Scardamalia \& Bereiter, 2003, p. 1371). The complexity of urgent societal problems and competitive demands of knowledge-based economies converge on the need to enhance knowledge building capabilities. Interest has grown in knowledge creation as a theoretical problem (Bereiter, 2002; Dennett, 1995), a cultural imperative (Homer-Dixon, 2000), a practical objective (Nonaka \& Takeuchi, 1995; Wickramasinghe, 2006), and a locus of sociopolitical controversy (Pestre, 2003).

Much of KSN's work has focused on what it means to create knowledge and how Knowledge Building can succeed in multidisciplinary, multi-age, multicultural contexts, in keeping with the goal of maximizing and democratizing society's knowledge-creating capacity and the need for inclusiveness that this entails. KSN's educational thrust is toward meeting knowledge era challenges by immersing participants in the practice of knowledge creation and innovation. Accordingly, educational challenges range from initiating young students into a knowledge creating culture from the beginning of their school years to the parallel and equally challenging need to bring knowledge building into the work lives of professional groups (e.g., teachers, 
bankers, and health care practitioners) who see their job as delivery of quality service, not advancing the state of their art.

KSN designs and pilot studies were initiated in the early 1990's, with report on student engagement by the mid 1990s (Scardamalia \& Bereiter, 1996). Since then KSN has evolved into an international and multidisciplinary network with teams in more than 20 nations addressing core problems of Knowledge Building theory, pedagogy, and technology. The work of philosophers, cognitive scientists, dialogue analysts, pedagogical innovators, measurement, and computer scientists, policy makers is enhanced through engagement in a network that includes diverse and distributed practicing communities. Engagement of those who are actually implementing knowledge creating practices and exploring challenges and opportunities provides a context for studying the process, testing new possibilities, and continually refining practices. Ideas and a broad range of artifacts are shared within KSN through online discussions and face-to-face events.

\section{Design of the KSN}

The design and functioning of KSN has been informed by Knowledge Building theory and supported by a computer-based Knowledge Building environment known as Knowledge Forum ${ }^{\circledR}$. The network as conceived of early on, and as it has continued, is a community-of-communities with the KSN as its "knowledge commons." In line with this model, there are many Knowledge Building communities working in local community spaces supported by Knowledge Forum (typically the local community establishes password protected spaces). We might think of these local community initiatives as establishing first-level working spaces: In the case of school settings, teachers and students develop their online knowledge space; in health-care settings, nurses and doctors develop their online knowledge space. Local communities can invite other sites to join them in the creation of a common, jointly constructed community space. Articles throughout the Winter 2009, V35.1 issue of CJLT and the present issue provide examples of knowledge spaces developed by various communities. KSN serves as the "metaspace" - the one common space for all community members..

$\mathrm{KSN}$ is not simply a portal or repository for the work of the broader community, although it can serve that purpose. The KSN represents an active Knowledge Building community in its own right. In addition to hosting virtual meetings and visits to different community knowledge spaces, with accompanying video conferences, webinars, and so forth, working groups from various communities assemble there to tackle specific challenges and to coordinate research and engineering initiatives. The KSN takes as its object of discourse the workings of the worldwide network engaged in advancing Knowledge Building theory, pedagogy, and technology.

The following section provides an overview of Knowledge Building dynamics within KSN at three levels of network design complexity, with Knowledge Forum supporting interactions at each level. The three levels should not be treated as distinct; rather, they represent Knowledge 
Building dynamics along a continuum, and there are interactions across the levels that are central to emergent growth of the network.

\section{Level 1: Fostering ideas contributed by participants to community knowledge to enable an idea-centered knowledge network.}

Bereiter and Scardamalia (Bereiter, 2002; Bereiter \& Scardamalia, 1996; Scardamalia, 1988) established the concept of "Knowledge Building" as a foundational approach to collective knowledge work for the improvement of epistemic artifacts (ideas, concepts, theories), models, prototypes, designs and so forth. They argue that there is a difference between learning and Knowledge Building. Learning is an activity directed towards enhancing personal knowledge (Polanyi, 1967), whereas Knowledge Building is a social, idea-centered process aimed at continually improving ideas represented as community knowledge (Bereiter, 2002; Bereiter \& Scardamalia, 1996; Hong \& Scardamalia, 2008; Scardamalia, 1999; Scardamalia \& Bereiter, 2003; Scardamalia, Bereiter, McLean, Swallow, \& Woodruff, 1989). Knowledge Building puts innovation in the foreground and suggests that even students at very young ages have the capacity to generate and improve ideas and that fostering students' innovative capacity should be regarded as a primary goal at all education levels.

The theoretical framework of Knowledge Building underlies the technological design of Knowledge Forum, a computer-supported Knowledge Building environment created to support sustained knowledge advancement. While it supports knowledge sharing, social networking, and attributes of other software, its primary goal is to support processes by which knowledge is created. It is a second-generation CSILE (Computer-Supported Intentional Learning Environment) designed to give ideas a public life and engage participants in continual improvement of ideas. As suggested above, Knowledge Forum is a multimedia community knowledge space to which participants contribute ideas in the form of notes to "views." A graphics tool is available to support participants in use of notes and views as virtual design spaces, to build models, create new organizational frameworks, and engage in collaborative problem solving without exclusive dependence on written discourse. Participants co-author; build-on, reference, and annotate notes; generate problems and add keywords; create riseabove notes to summarize different notes that contain related ideas; generate multimedia objects (e.g., graphics, video); and in a variety of other ways work to improve ideas. Figure 1 shows select interface design features of a Knowledge Building note.

At its simplest level of network complexity, Knowledge Forum is designed as an environment to record and support development of ideas.

Knowledge Society Network: Toward a Dynamic, Sustained 


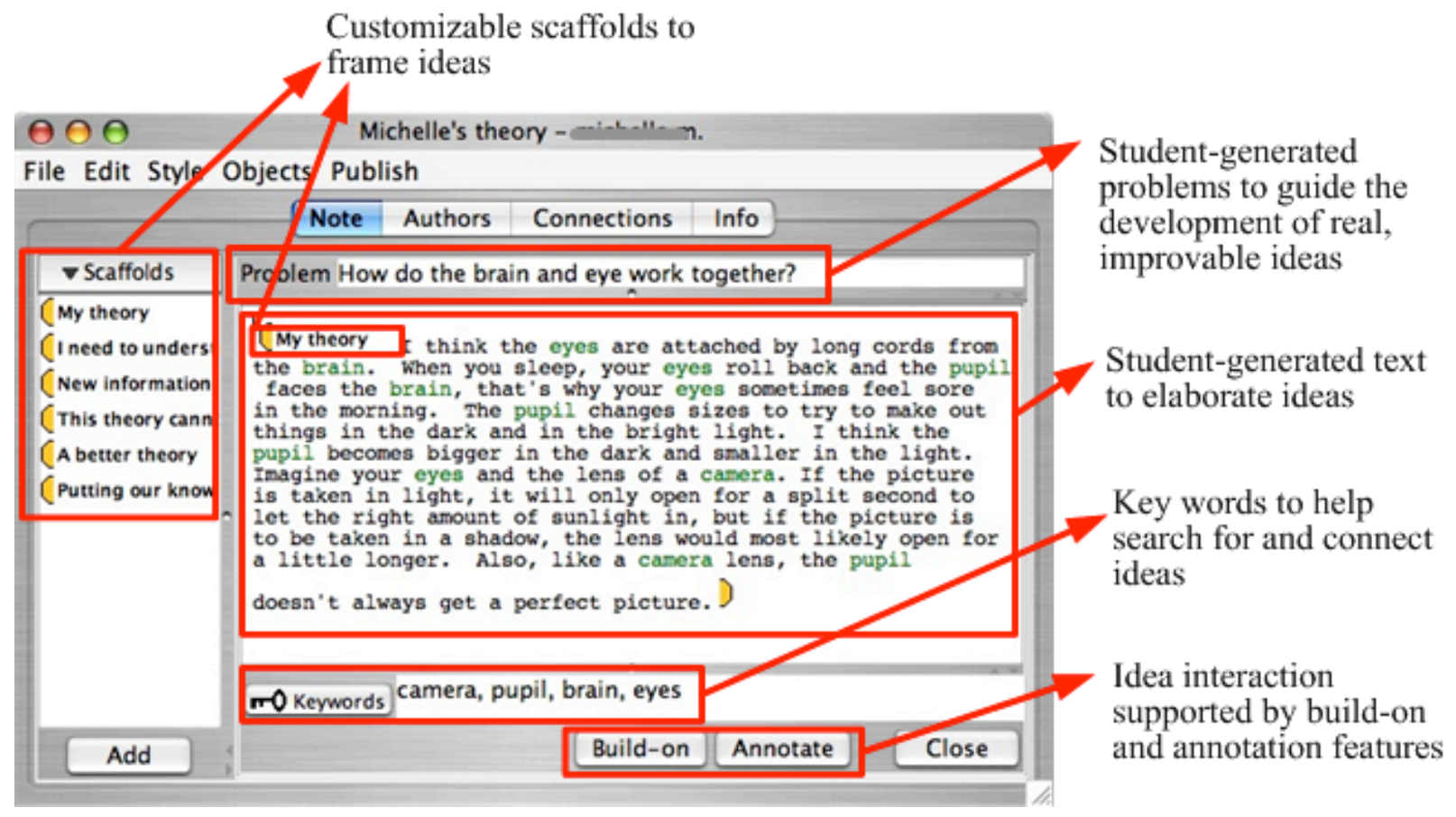

Figure 1: Design features of a Knowledge Forum note to support idea generation and improvement (adapted from Knowledge Forum 4.6 online manual at http://ikit.org/kf/46/help/).

Level 2: Networks of ideas--ideas linked, referenced, built on, annotated, reconceptualized by participants--leading to sustained knowledge innovation.

According to social network theory (Newman, 2003), when explaining complex real-world social phenomena, the attributes of individual entities are less important than their relationships (or ties) with other individual entities within the network (see also Philip, present issue). The process of Knowledge Building is fundamentally social and idea-centered (Hong \& Sullivan, 2009; Scardamalia, 1999). Ideas and participants who work with these ideas are essential entities of Knowledge Building networks. To understand the complex dynamics of Knowledge Building, it is necessary to understand the interactions between ideas and participants in the networks to which they belong.

The Knowledge Forum environment facilitates not only participant interaction but also explicit linking of ideas in ways that support productive idea improvement. Figure 2 illustrates a Knowledge Forum view. A view represents a knowledge or problem-solving space which is set by participants to address a particular area of inquiry (e.g., professional development), a subject area (e.g., memetics) or much more specific issues of interest to the community. Conceptually, a Knowledge Forum view is also designed to be a knowledge visualization tool for representing higher-order organizations and representations of ideas. Through the creation of rise-above notes and graphical organizations, users signal the rising status of ideas, as contrasted with the typical discourse threads and repositories that provide no means of showing higher-order organizations (Scardamalia, 2003b).

Knowledge Society Network: Toward a Dynamic, Sustained Network for Building Knowledge 
Users are also encouraged to work in multiple views, to create links between views, and to create views-of-views (a top level view that shows connections to other views). Figure 2 illustrates view links that help serve these purposes.

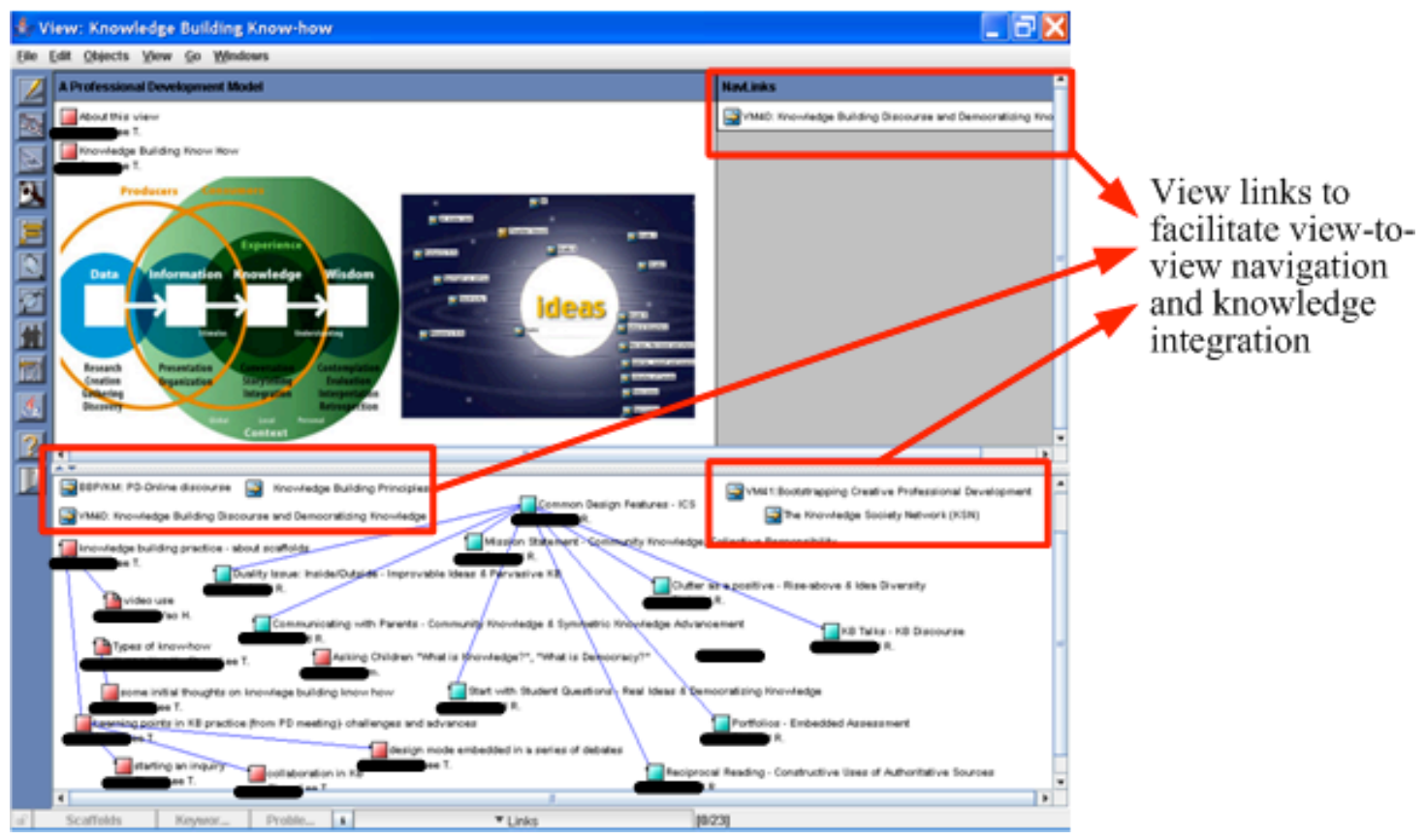

Figure 2: An example of a Knowledge Forum view in the KSN.

Rise-above notes and views are designed to help achieve the rise above Knowledge Building principle. In line with this principle, at all levels users are encouraged to create metaperspectives to continually advance ideas and go beyond idea exchange to higher-order integrations. Most Internet-based, education-oriented knowledge networks are designed to be information sharing networks (Bereiter \& Scardamalia, present issue; Zhang, 2009). The KSN, in contrast, is designed to support sustained idea improvement through integrated and balanced knowledge-building dynamics.

At this second or middle level of network complexity, Knowledge Forum is designed to develop networks of linked ideas.

Level 3: Network-of-networks--ideas linked across work units and across nations and time zones- to support distributed expertise and integration of knowledge work across different knowledge spaces.

Technologies are increasingly created by self-organizing knowledge workers (Rycroft, 2003). For example, Linux is developed by an essentially volunteer, self-organizing community of thousands of programmers who collaborate on diversified ideas through constant exchange of open source code (Evans \& Wolf, 2005). The Internet itself has been considered the single largest network system that self-organizes (Fuchs, 2005), Internet-based collectives hold promise for increasing society's ingenuity, through less hierarchical and more distributed, opportunistic, and global configurations, with potential for greatly increasing idea productivity

Knowledge Society Network: Toward a Dynamic, Sustained Network for Building Knowledge 
(Homer-Dixon, 2006). Accordingly, there is an increasing trend to design self-organizing innovation networks (Rycroft, 2003), whether Internet-based or not.

According to Prehofer and Bettstetter (2005), a system must consist of the following features to be considered self-organizing: (1) It is composed of individual entities, with a certain structure and functionality; (2) it is organized without external, central dedicated control. The individual entities interact directly with each other in a distributed peer-to-peer fashion; (3) the application of simple behavior at the microscopic level leads to sophisticated organization at the macroscopic level; (4) it is adaptable with respect to changes in the system.

Building on the arguments laid out in the previous sections, the KSN operates in line with specifications listed above (Prehofer \& Bettstetter, 2005): (1) it is composed of individual participants who interact directly and freely with one another in a peer-to-peer fashion, with organization and functionality locally and within the broader community to support and sustain knowledge advancement; (2) individual entities interact directly with each other in a distributed peer-to-peer fashion (see, for example, Laferrière, et al., present issue); (3) application of sustained idea improvement at the microscopic level leads to sophisticated organization of community knowledge at the macroscopic level; and (4) the KSN is an inclusive community-ofcommunities or network-of-networks with a scalable social structure and adaptive technological functionality that allows the network as a whole to grow and adapt to changing needs. It helps to coordinate the work of local communities while facilitating cross-community linkages, with teams of researchers and engineers working continuously to advance Knowledge Building theory, pedagogy, and technology, including practical know-how with diverse communities so as to make a difference to a knowledge society.

At the third level of network complexity, Knowledge Forum is designed to support a community-of-communities or network-of-networks.

An important component of our work is assessment of KSN's effectiveness as a meta-database supporting and coordinating the work of broad-based, diverse sub-groups or communities and at the same time serving as a hub of innovation. The Knowledge Forum database that hosts KSN is, in essence, a collection of views that provide important traces of the discourses of the extended community. Given the international nature of the enterprise most work is conducted online and through virtual meetings, thus it is possible to analyze the discourses from those events. In this study we analyze these discourses to determine if KSN helps to provide a sustaining force for knowledge building developments.

\section{Toward a Self-Organizing Knowledge Innovation Network}

As elaborated above, understanding relationships is key to explaining complex social phenomena and patterns in a network. But what measures or types of relationships are most worthy of analysis? That is a critical question as uncovering meaningful social network patterns depends highly on the measures or types of relationships analyzed. Social Network Analysis (SNA) has been developed to uncover important relationships, and for most knowledge networks, the core relationship exists between people and the knowledge objects they create 
(e.g., a note, an email, or a piece of information), with people and these objects each representing an important dimension of the analysis. Typically researchers settle on relational measures and run the analysis, without comparison to different patterns that might result from considering different dimensions of the relationship. Perhaps more importantly, when it comes to the matter of assessing networks in relation to their knowledge-advancing capacity, social networking usually focuses on people-to-people interactions, not so much on "the social life of information" (Brown \& Duguid, 2002). Information acquires new meaning and is improved not just through social interactivity but also idea interactivity. It is possible to have weak and strong interactivity on both social interactivity and idea interactivity dimensions.

The effectiveness of a Knowledge Building network depends on high participant and high idea interactions. Sustaining network interactivity on both dimensions represents a significant challenge as most networks tend toward high social, low idea interactivity or low on both dimensions, and are not sustained over extended periods of time.

The KSN as a self-organizing knowledge innovation network aims to support high levels of both participant and idea interaction:

a) Participant interaction: Members interact with one another to co-work on emergent and shared problems. In each problem space, they engage in Knowledge Building discourse by reading and building on peer contributions and rising above diverse ideas to construct more advanced and coherent accounts. Intensive participant interactions are also needed to bring participants from the peripheral to the core activity of the organization (Lave, \& Wenger, 1989). Existing research indicates a significant correlation between the number of participants involved in a conceptual thread of online discourse and the depth of understanding achieved (Zhang, Scardamalia, Lamon, Messina, \& Reeve, 2007).

b) Idea interaction: Ideas flow and connect across content domains and contexts as the involved participants (e.g., contributors, readers) dynamically form around diverse themes of inquiry and ideas are brought into contact opportunistically. Facilities within Knowledge Forum support opportunism in idea interaction. For example, nearestneighbour searches, searches using scaffolded terms and keywords, semantic analyses, and visualizations all operate to create idea networks. As indicated by Bielaczyc and Collins (2006), dynamic interaction between ideas as well as between people helps to foster spread of ideas and create new opportunities for knowledge creation.

To address the issue concerning effective relational measures for assessing the KSN, the following three measures were developed based on the three levels of network complexity and connectivity identified above. As Figure 3 indicates, these correspond to (1) contribution (the number of notes a participant contributes to a view in the KSN. This provides indication of effort to develop ideas); (2) sharing a problem space (the number of links between two participants in the KSN provides indication of social interaction aimed at developing ideas); and (3) working in multiple problem spaces (the number of links between views in the KSN provided indication of idea interaction aimed at exchanging ideas across diverse contexts).

Knowledge Society Network: Toward a Dynamic, Sustained Network for Building Knowledge 


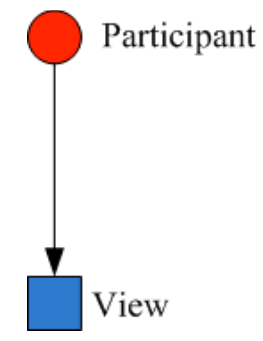

3a: Contribution

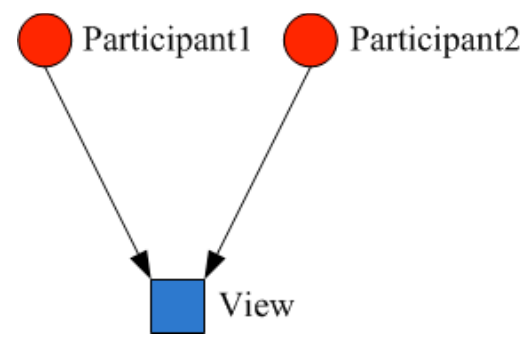

3b: Shared problem space

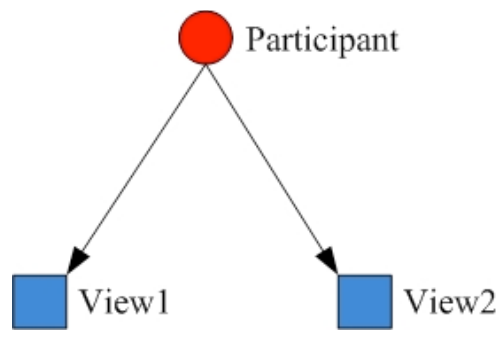

3c: Multiple problem spaces

Figure 3: Three basic relational units of analysis for social- and idea interaction analyses

A central argument for an idea-centered Knowledge Building approach is that ideas, once generated, have a public life to support the process of continual improvement. But this does not imply that all ideas will be transformed equally. Depending on the dynamics of a network, some ideas may be connected, elaborated and synthesized more intensively than others. Stated differently, once generated and contributed to a community space, ideas may take very different evolutionary courses and be worked on in different knowledge networks. Using the two basic types of interactions, participant interaction and idea interaction, as criteria to evaluate how ideas are improved, a two-by-two network configuration (see Figure 4) shows four possible network models based on participant and idea interaction. In Figure 4, the $\mathrm{Y}$ axis represents the strength of participant interaction measured by the number of connections between any two participants who work in the same view (the shared problem space measure introduced above). The $X$ axis represents the intensity of idea interaction measured by the number of connections between two views worked in by the same participant, (the multiple problem spaces measure introduced above). Of the four network models, the Sustained Knowledge Innovation Network tends to represent the optimal type for knowledge innovation, with both strong participant and idea interaction. Networks for open source programmers provide a good example (Evans \& Wolf, 2005). Emerging Network, with relatively weak participant and idea interaction, represents a network with the least capacity for knowledge innovation. It seems fair to say that most networks fall into this category. Intensive Participant Interaction Network has strong participant interaction with many participants co-working on shared topics but weak idea interaction across topics and themes. In these networks innovation capacity is limited by lack of fresh perspectives and connections (Chubin, 1976; Granovetter, 1983). In contrast, a Frequent Idea Interaction Network has strong idea interaction and sharing but weak participant interaction surrounding shared focal themes; its innovation potential is accordingly limited because there is not enough social interaction around ideas to drive toward increasingly deep understanding (Kling \& Rosenberg, 1986). Each network model could represent a complete, self-sustained network, or it could represent a sub-network within a larger network. The question is how to develop more innovative networks for sustained participant and idea development.

Knowledge Society Network: Toward a Dynamic, Sustained 


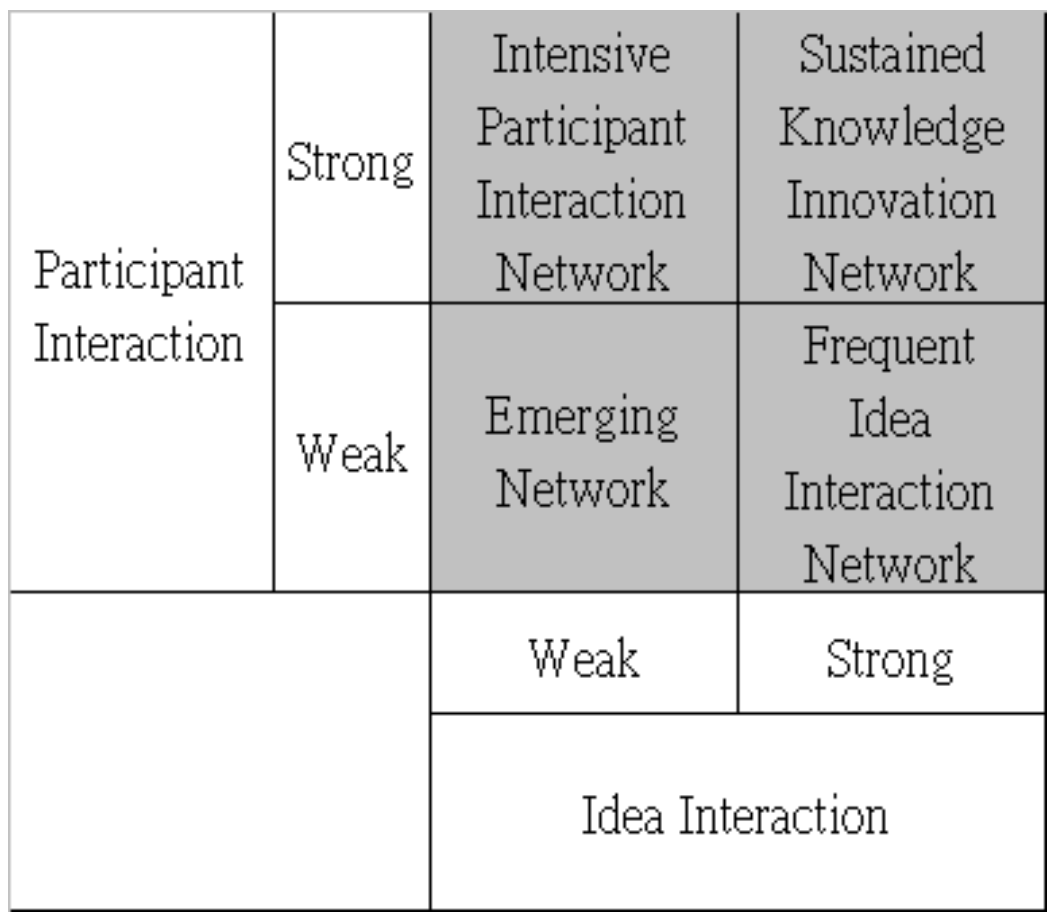

Figure 4: Four network models.

Using the four network model elaborated in Figure 4 as an analytical framework, this study investigates the relationships between network structures and potential for knowledge advancement in the KSN. In particular, we analyzed participant and idea interactions recorded in Knowledge Forum over four years. The questions addressed through this research were: (a) What was the overall network growth of the KSN over four years? (b) What types of participant and idea interactions are evident? (c) To what extent is KSN a sustained and productive knowledge network in light of the four types of network structures identified above? Addressing these questions will help identify strengths and weaknesses and inform further refinement of KSN.

\section{Method}

\section{Participants}

Participants in the KSN over the four years of this investigation were 353 members from various disciplines (more than 20), sectors (including education, health care, community organizations, and businesses) and cultures (nations from the Americas, Asia, and Europe).

\section{Data Sources}

Knowledge Forum, the technological infrastructure for the KSN, captures the discourse of participants and the artifacts recorded there. This is the data source we tapped for our inquiry into patterns of participant and idea interaction. Data analysis was aided by the use of the Analytic Toolkit (Burtis, 1998) that underlies Knowledge Forum. Relational measures as indicated in Figure 3 and elaborated below provide the basis for social network analyses. 


\section{Data Analysis}

The analyses of online discourse involved a set of measures adopted from social network analysis (SNA), which provides methods for examining information flow in a community or organization based on mathematical graph theory (Wasserman \& Faust, 1994). The three relational measures introduced above were used for SNA analyses: (1) Contribution--number of notes a participant contributed to a view (Figure 3a). The more notes contributed to a view, the stronger the relationship between that participant and the work reflected in that view. (2) Shared problem space--two participants contribute to the same view (Figure 3b). Intensity of this relational measure is assessed by the number of views to which two participants contribute. The more participants work in a common problem space, the greater the likelihood of participant interaction. (3) Multiple problem space--two views are worked in by the same participant (Figure 3c). Intensity of this relational measure is assessed by the number of participants working in the same two views. If a participant is working in multiple problem spaces, there is greater likelihood of creating connections between ideas in these different problems spaces and, accordingly, taking them to greater depth.

The three different relational measures represent an attempt to assess network dynamics from different perspectives. We do not additionally test for literal or explicit interactions between participants and ideas, nor assess the extent to which ideas are taken to greater depth. Our goal at this point is to extend the range of conceptual models and relational measures available, as a first step toward extending our understanding of the social- and idea-interaction dynamics of knowledge networks.

The UCINET SNA software tool (Borgatti, Everett \& Freeman, 2002) was employed for data network analysis in this study. Specific SNA measures are elaborated along with the results.

\section{Findings and Discussion}

\section{Overall Growth}

Analysis of the KSN was conducted in 2005-2007 when the first author was a postdoctoral fellow working at the Institute of Knowledge Innovation and Technology. For the four years previous to this investigation, the KSN had grown (see Table 1) from 47 to 353 active members and from 13 to 172 views (excluding personal portfolio views), with each view addressing issues of Knowledge Building theory, practice and technology, including issues of professional development and educational reform (see Teo, Zhang, Hong, Gan \& Scardamalia, 2006, for an overview). Its growth and sustainability over time suggests the possibility of achieving increasingly high levels of knowledge advancement. 
Table 1: Cumulative Growth in KSN.

\begin{tabular}{|l|cccc|}
\hline & Year 1 & Year 2 & Year 3 & Year 4 \\
\cline { 2 - 5 } $\begin{array}{l}\text { Number of participants } \\
\text { and contributors) }\end{array}{ }^{a}$ (readers & 47 & 200 & 290 & 353 \\
Number of readers & 47 & 200 & 290 & 353 \\
Number of contributors & 10 & 116 & 213 & 274 \\
Number of views & 13 & 55 & 135 & 172 \\
Number of notes contributed & 67 & 1042 & 3868 & 4472 \\
Ratio (contributors over readers) & 0.21 & 0.58 & 0.73 & 0.78 \\
\hline
\end{tabular}

Note: Readers do not necessarily contribute notes but contributors must be readers (minimally they read the note they contributed).

\section{Participant Interaction Patterns}

To understand how participants interact and whether their interactions are sustained across years, we used a matrix correlation to test the association between an observed and an expected relational network (see Borgatti et al., 2002 for a detailed explanation), using "shared problem space" as a unit of analysis. The results (Tables 2-4) show significant positive correlations between same contributors' (i.e., participants who contribute notes and are not simply readers in the network) in any one year and the next. For example, as Table 3 indicates, the same 113 contributors who worked in the KSN in Year 2 continue working together with one another throughout Years 2-4. Participants collectively worked in the same problem spaces pertaining to Knowledge Building theory, practice and technology in a sustained manner over a long period of time. 
Table 2: Matrix correlation: association between contributors to the network, years 1, 2, and 3; interactions between the same 10 contributors in years 2, 3, and 4 respectively.

\begin{tabular}{|c|c|c|c|c|}
\hline & \multicolumn{4}{|c|}{$\begin{array}{c}\text { Interaction }{ }^{a} \text { among the same contributors in } \\
\text { different years }\end{array}$} \\
\hline & $\begin{array}{l}\text { Year } 1 \\
(\underline{n}=10)\end{array}$ & $\begin{array}{l}\text { Year } 2 \\
(\underline{n}=10)\end{array}$ & $\begin{array}{l}\text { Year } 3 \\
(\underline{n}=10)\end{array}$ & $\begin{array}{l}\text { Year } 4 \\
(\underline{n}=10)\end{array}$ \\
\hline \multicolumn{5}{|l|}{ Contributors $(\underline{n}=10)$ in Year 1} \\
\hline Interaction in Year 1 & 1 & $.430 *$ & $.320^{*}$ & $.367^{*}$ \\
\hline Interaction in Year 2 & . & 1 & $.930 * *$ & $.723^{* *}$ \\
\hline Interaction in Year 3 & . & . & 1 & $.791^{* *}$ \\
\hline Interaction in Year 4 & . & . & . & 1 \\
\hline
\end{tabular}

Notes: The basic "shared problem space" relational measure (number of views to which two participants contribute) is used for this analysis.

${ }^{*} \underline{\mathrm{p}}<.05 * * \underline{\mathrm{p}}<.01$ (both 2-tailed).

Table 3: Matrix correlation - association between contributors to the network, years 2, and 3; interactions between the same 113 contributors in years 3 and 4 respectively.

\begin{tabular}{|c|c|c|c|}
\hline & \multicolumn{3}{|c|}{$\begin{array}{l}\text { Interaction }{ }^{a} \text { among the same } \\
\text { contributors in different years }\end{array}$} \\
\hline & $\begin{array}{l}\text { Year } 2 \\
(n=113)\end{array}$ & $\begin{array}{l}\text { Year } 3 \\
(n=113)\end{array}$ & $\begin{array}{l}\text { Year } 4 \\
(\underline{n}=113)\end{array}$ \\
\hline \multicolumn{4}{|l|}{ Contributors $(\underline{n}=113)$ in Year 2} \\
\hline Interaction in Year 2 & 1 & $.642 * *$ & $.463^{* *}$ \\
\hline Interaction in Year 3 & . & 1 & $.730 * *$ \\
\hline Interaction in Year 4 & . & . & 1 \\
\hline
\end{tabular}

Notes: The basic "shared problem space" relational measure (number of views to which two participants contribute) is used for this analysis.

${ }^{* *} \underline{p}<.01$ (2-tailed).

Knowledge Society Network: Toward a Dynamic, Sustained 
Table 4: Matrix correlation - association between contributors to the network, year 3; interactions between the same 139 contributors in year 4.

\begin{tabular}{|c|c|c|}
\hline & \multicolumn{2}{|c|}{$\begin{array}{l}\text { Interaction among the same } \\
\text { contributors in different years }\end{array}$} \\
\hline & $\begin{array}{l}\text { Year } 3 \\
(\underline{n}=139)\end{array}$ & $\begin{array}{l}\text { Year } 4 \\
(\underline{n}=139)\end{array}$ \\
\hline \multicolumn{3}{|l|}{ Contributors $(\underline{n}=139)$ in Year 3} \\
\hline Interaction in Year 3 & 1 & $.614^{* *}$ \\
\hline Interaction in Year 4 & . & 1 \\
\hline
\end{tabular}

Notes: The basic "shared problem space" relational measure (number of views to which two participants contribute) is used for this analysis.

$* * p<.01$ (2-tailed).

To further explore participant interaction patterns, a core/periphery analysis was performed to identify which participants belong in the core and which belong in the periphery by fitting a mathematical model to the network data (Borgatti \& Everett, 1999). In addition, network degree centralization was calculated. The degree of participation in SNA means the total number of connections between a participant and other participants in a network; and degree centralization is the mean degree number (Freeman, 1979). As Table 5 shows, while the core group has fewer participants $(\underline{n}=58)$ than the periphery group $(\underline{n}=201)$, its network degree centralization is significantly higher than that of the periphery group. The finding of high centralization in the core group implies that participant interactions occur mostly among the core members.

Table 5: Network Degree Centralization.

\begin{tabular}{ccccc} 
& $\underline{\mathbf{n}}$ & Mean Degree $^{\mathrm{a}}$ & $\underline{\mathrm{SD}}$ & t test \\
\hline Core group & 58 & 288.86 & 253.02 & \\
Periphery group & 201 & 35.5 & 24.66 & $7.62^{* *}$ \\
\hline
\end{tabular}

Notes: The degree of participation in SNA means the total number of connections between a participant and other participants in a network; and degree centralization is the mean degree number (Freeman, 1979).

$* * \mathrm{p}<.001$

Knowledge Society Network: Toward a Dynamic, Sustained 
As a way of triangulation, Figure 5 shows the visual patterns, in which the members in the core group demonstrate strong ties with one another and form a single stand-alone community (5a) whereas the members in the periphery group show weak ties and form many small local communities, clustered by years (5b). Improving KSN will require enhanced participant interaction between nested sub-communities in the periphery.

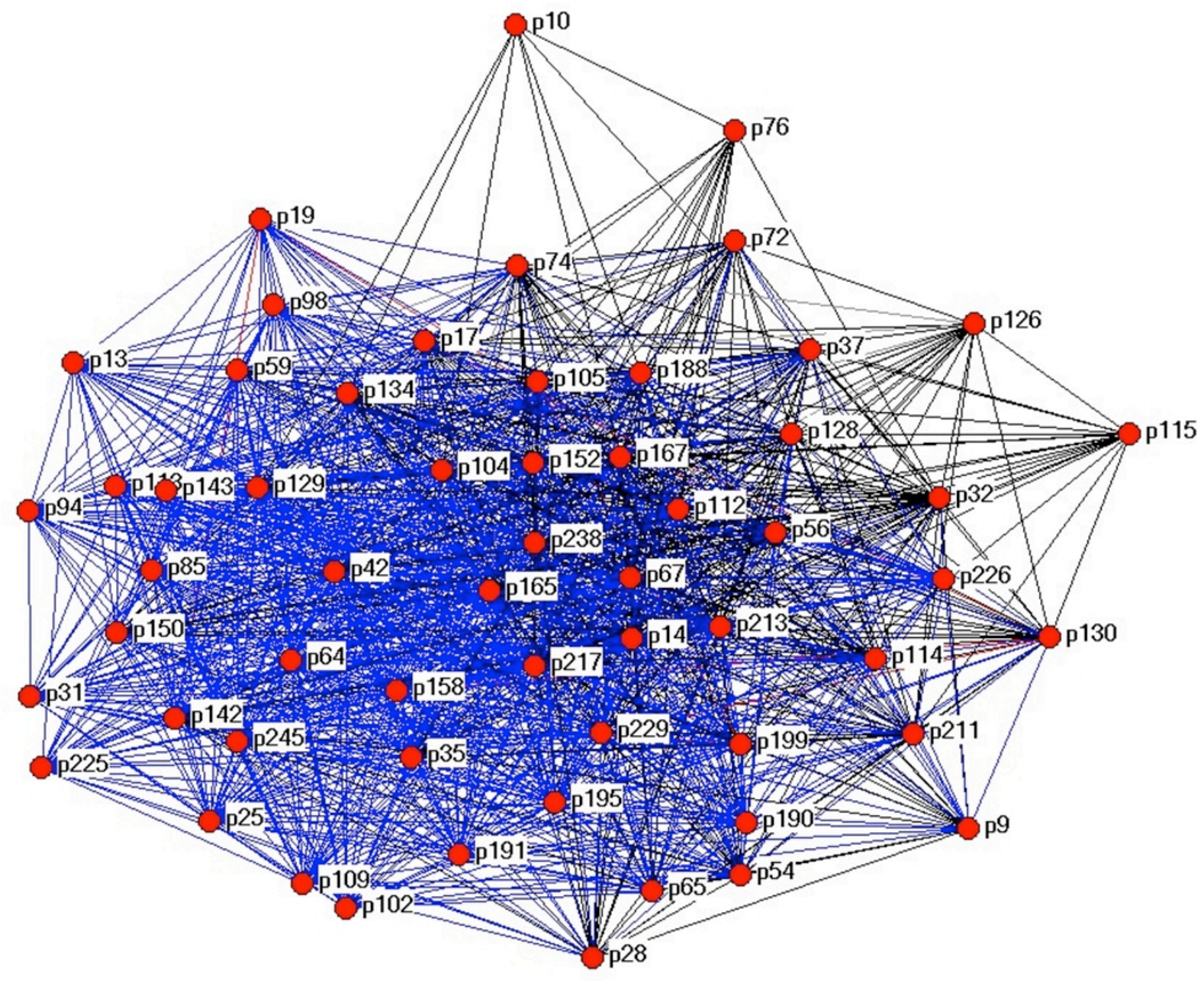

5a: Strong-Tie Pattern in the Core Group

Knowledge Society Network: Toward a Dynamic, Sustained Network for Building Knowledge 


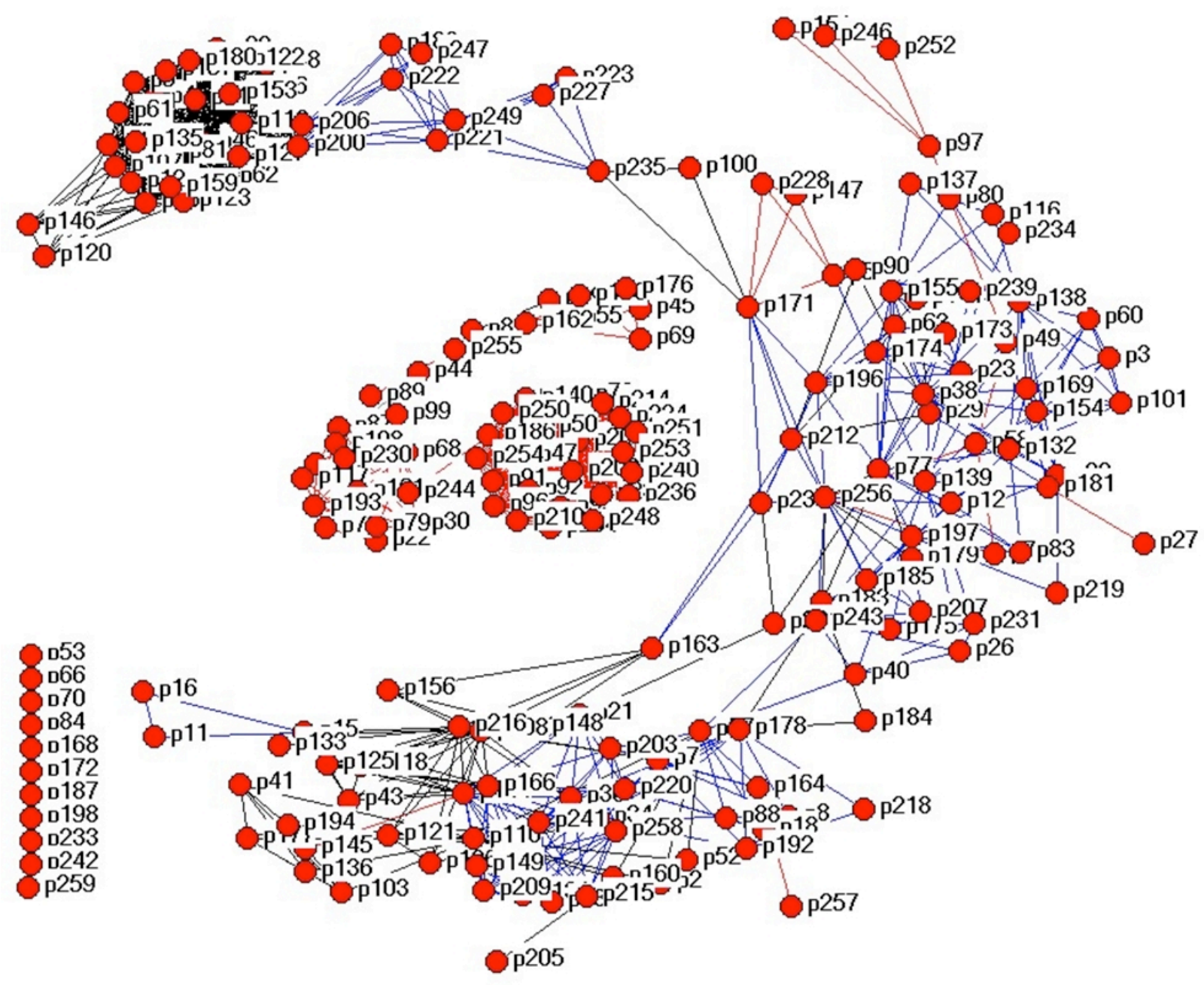

5b: Weak-Tie Pattern in the Periphery Group

Figure 5: Network patterns for participant interaction in the KSN. In both figures, unit of analysis is "shared problem space," in which each red-circled-node represents a participant and each tie represents at least one view in which two participants work together. Colours of lines refer to years: Year 1 (green), 2 (black), 3 (blue), and 4 (red). The Year 1 ties (green) are too few to be seen in both figures.

\section{Idea Interaction Patterns}

To understand how one year's idea interaction network relates to another year's, a matrix correlation (Borgatti et al., 2002) was conducted using "multiple problem spaces" as a unit of analysis. The results showed virtually no association between years. While this was not expected, it is, in retrospect, not surprising as new views in the KSN were continuously created to advance knowledge; as a result, an active view in one year usually did not remain active in the following years. Also, the measure does not take into account the view-linking functionality of Knowledge Forum, as shown in Figure 2, by which authors link one view to another. As 
participants finish one initiative they often use a view as an "archive," and then add a link for that view to the new view. This form of connection is not reflected in the analysis we used. This points to the need for more dynamic view-linking measures to capture the fact that views are emergents of the Knowledge Building process rather than predefined knowledge structures and the analyses should take into account linked views. Lack of statistically significant correlations may mask the fact that idea interactions existed that we were not able to identify with our current analyses. To further explore idea-interaction patterns, the same core/periphery analysis (Borgatti \& Everett, 1999) mentioned above was performed to identify which views belong in the core group and which belong in the periphery group by fitting a mathematical model to the network data (Borgatti \& Everett, 1999). The result showed that although the core group contains fewer views $(\underline{n}=60)$, its network degree centralization (see Freeman, 1979) is significantly higher than the periphery group (Table 6). The finding of high centralization indicates that idea interactions occur more frequently in views of the core group.

Table 6: Network Degree Centralization.

\begin{tabular}{ccccc}
\hline & $\underline{\mathbf{n}}$ & Mean degree $^{\mathrm{a}}$ & $\underline{\mathbf{S D}}$ & t test \\
\hline Core group & 60 & 532.52 & 117.08 & \\
Periphery group & 112 & 171.65 & 104.85 & $19.97^{* *}$ \\
\hline
\end{tabular}

Notes: The degree of participation in SNA means the total number of connections between a participant and other participants in a network; and degree centralization is the mean degree number (Freeman, 1979).

$* * \underline{p}<.001$

Figure 6 shows patterns of similarities in both core and periphery groups. It was found that they both have clear-cut clusters between years (represented by colours of ties), in which there were very few views being linked together (e.g., there are only five views in the core and six in the periphery linked between Year 2 and Year 4). This confirms the above idea-interaction pattern showing that new views emerge from year to year. Improving the KSN will require enhancing idea interaction between views, in addition to developing more powerful means to show and analyze increasingly comprehensive and linked spaces. Next efforts will consider more comprehensive measures, including references, keywords, semantic overlap, and so forth. Presumably these will be more sensitive to idea linkages, so that we can determine the extent to which moving on to a new problem space means abandoning prior spaces versus recreating the ideas represented there at some more comprehensive and deeper level. Addressing this challenge will require more sophisticated measurement tools as well as more sophisticated linking structures between views and between notes in views. Such tools would help identify important, big ideas embedded in different notes and views; more sophisticated and constructive idea-interactions should result. 


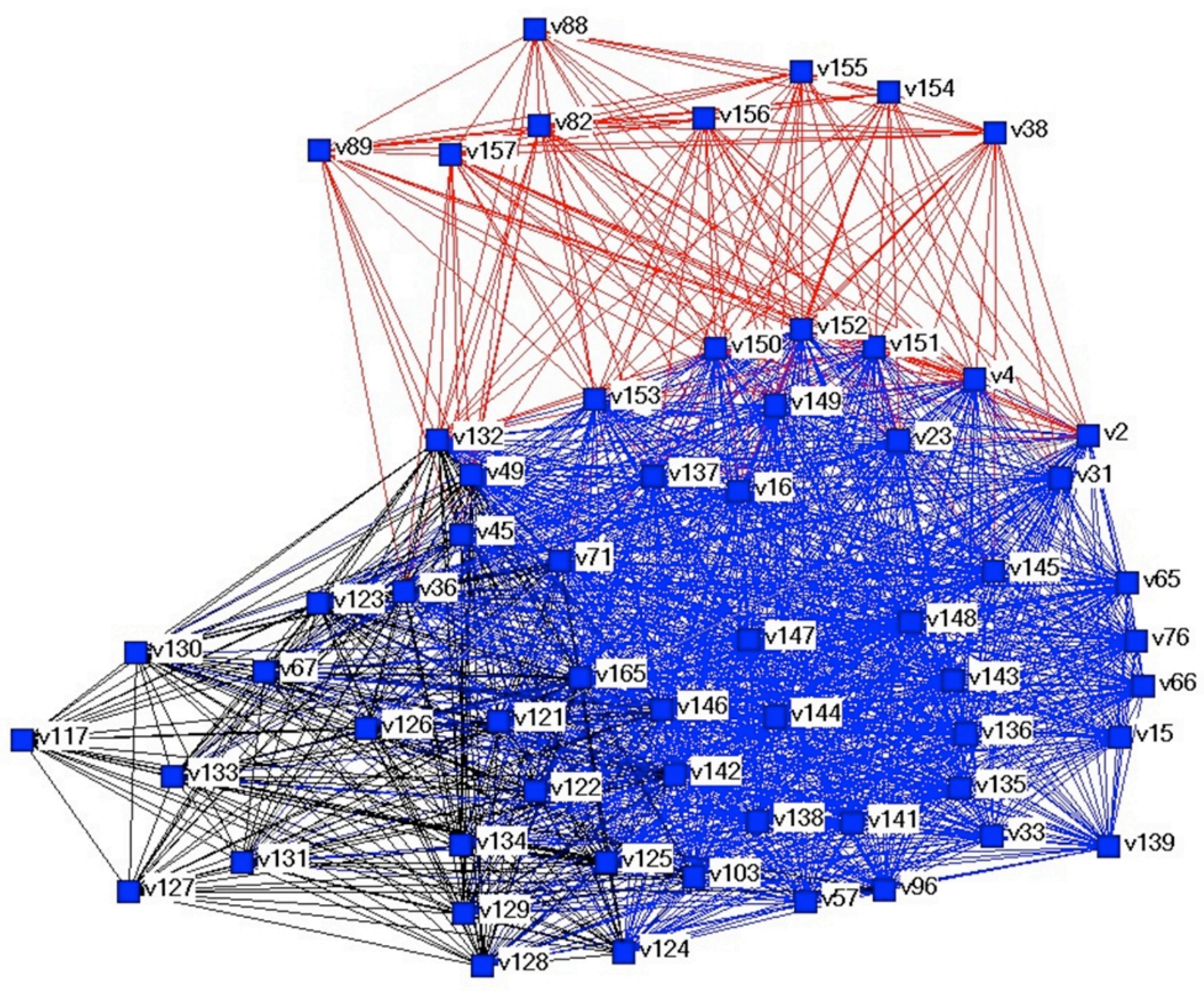

6a: Strong-Tie Pattern in the Core Group

Knowledge Society Network: Toward a Dynamic, Sustained Network for Building Knowledge 


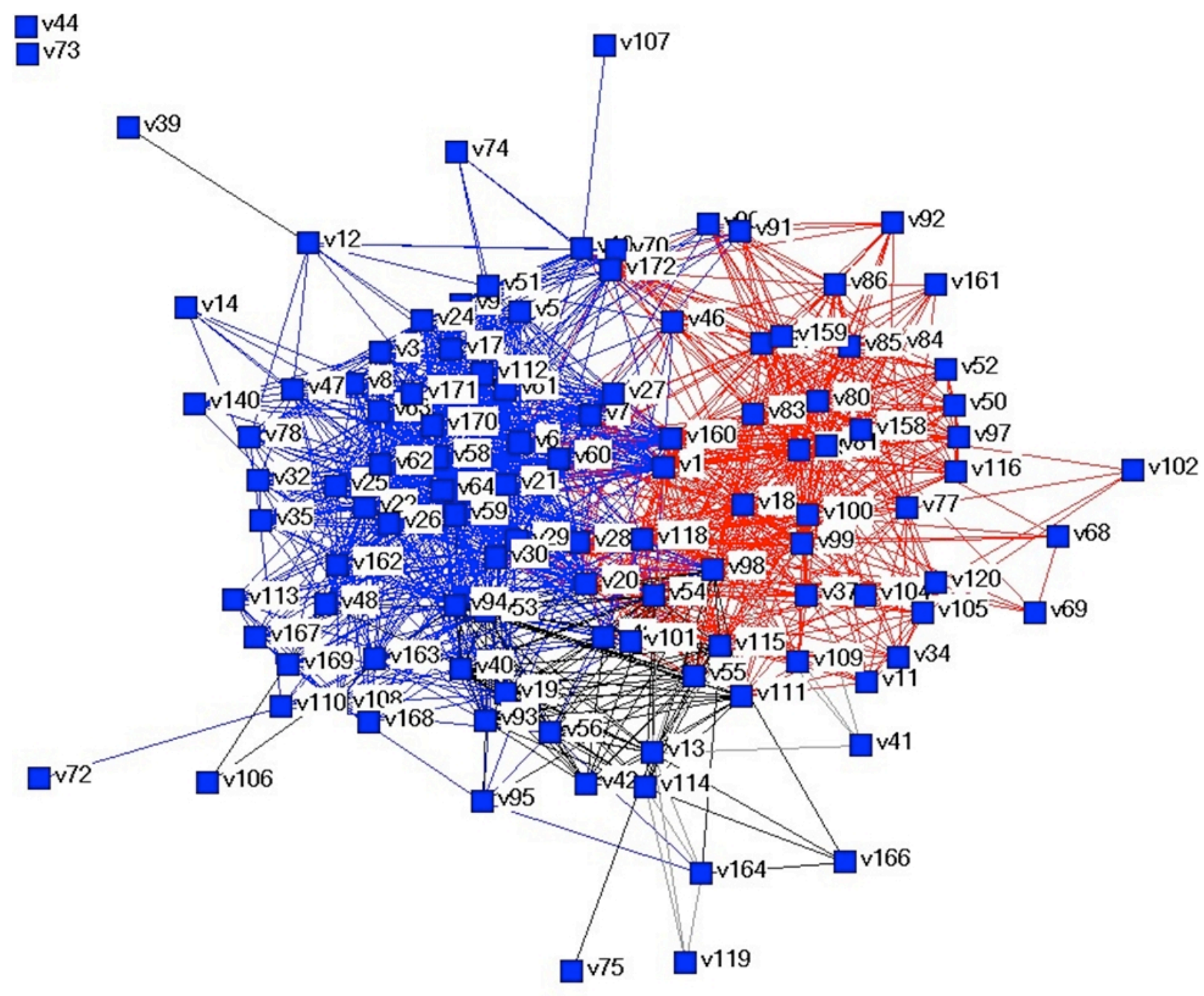

6b: Weak-Tie Pattern in the Periphery Group

Figure 6: Network patterns for idea interaction in the KSN. In both figures, unit of analysis is "multiple problem spaces," in which each blue-squared-node represents a view and each tie represents at least one contributor who works in both views. Colours of ties refer to years: Year 1 (green), 2 (black), 3 (blue) and 4 (red). The Year 1 ties (green) are too few to be seen in both figures.

The above analyses suggest that there was sustained growth over four years, and intensive participant and idea interaction in the KSN, especially in the core groups. While informative, it is not clear how this network compares to other networks, as there is little baseline data and these overall and uni-dimensional analyses were not able to explain the meta-relationships between participant and idea interaction (for instance, how ideas might interact with each other, within the weak, peripheral participation network). To capture more subtle network patterns for Knowledge Building in the KSN, it is necessary to employ two-dimensional analysis by taking both participant and idea interaction into account at the same time. To this end, we 
analyzed the KSN and identified four sub-networks corresponding to those in Figure 4 . As the reader might recall, these were as follows: (a) Sustained Knowledge Innovation Network-with strong participant and idea interaction; (b) Emerging Network - with weak participant and idea interaction; (c) Intensive Participant Interaction Network-with strong participant interaction but weak idea interaction; and (d) Frequent Idea Interaction Network-with weak participant interaction but strong idea interaction (also see Figure 7). Each sub-network represents a type of network dynamic, and it is interesting that all four of these dynamics are evident in KSN.

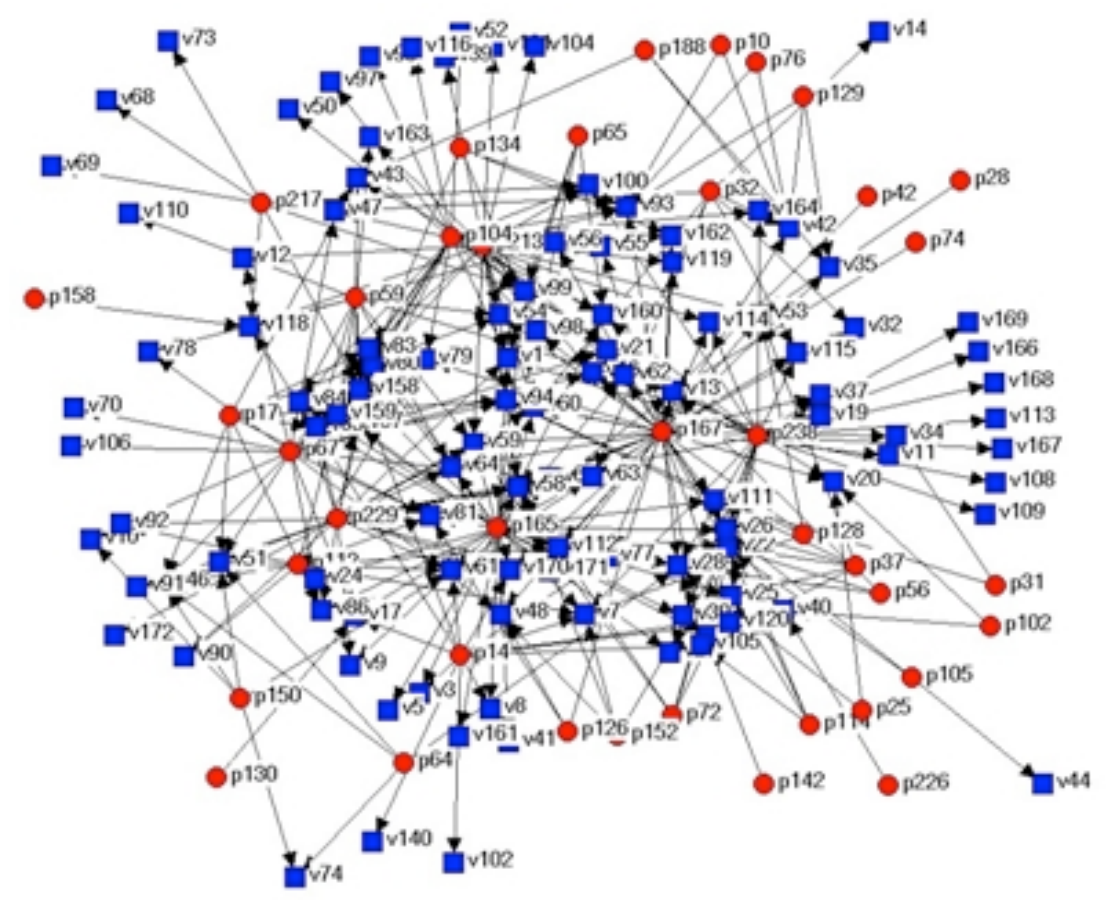

Intensive Participant Interaction Network

Knowledge Society Network: Toward a Dynamic, Sustained 


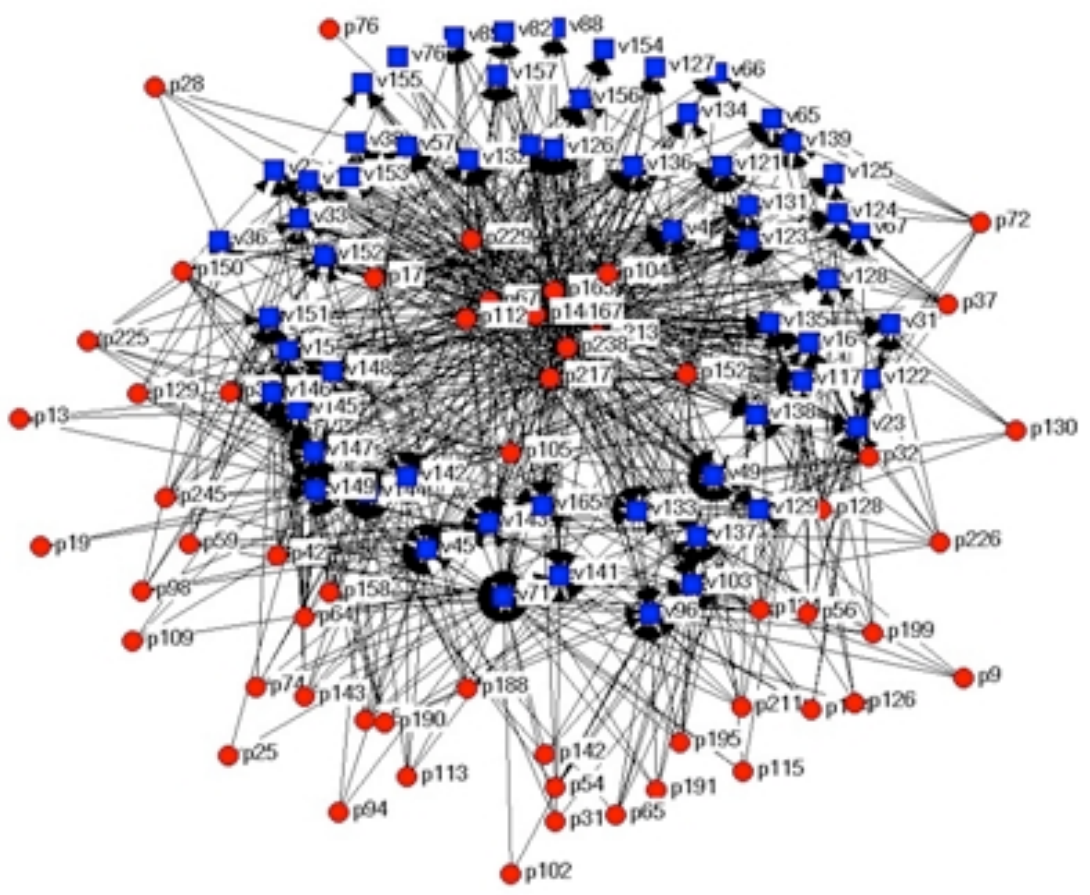

\section{Sustained Knowledge Innovation Network}

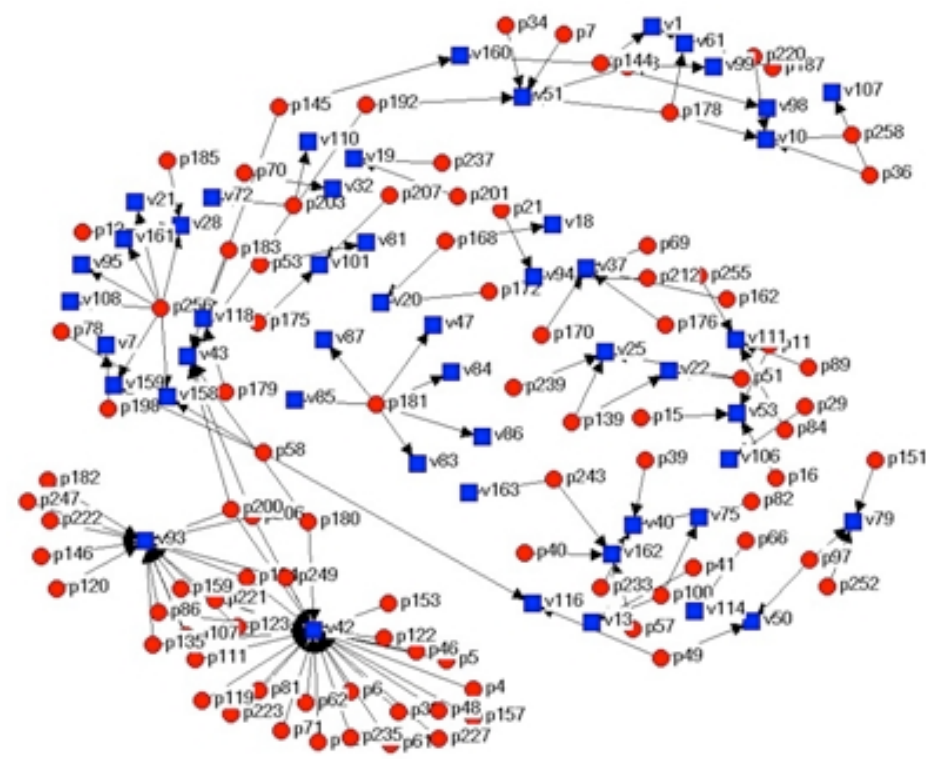

Emerging Network

Knowledge Society Network: Toward a Dynamic, Sustained 


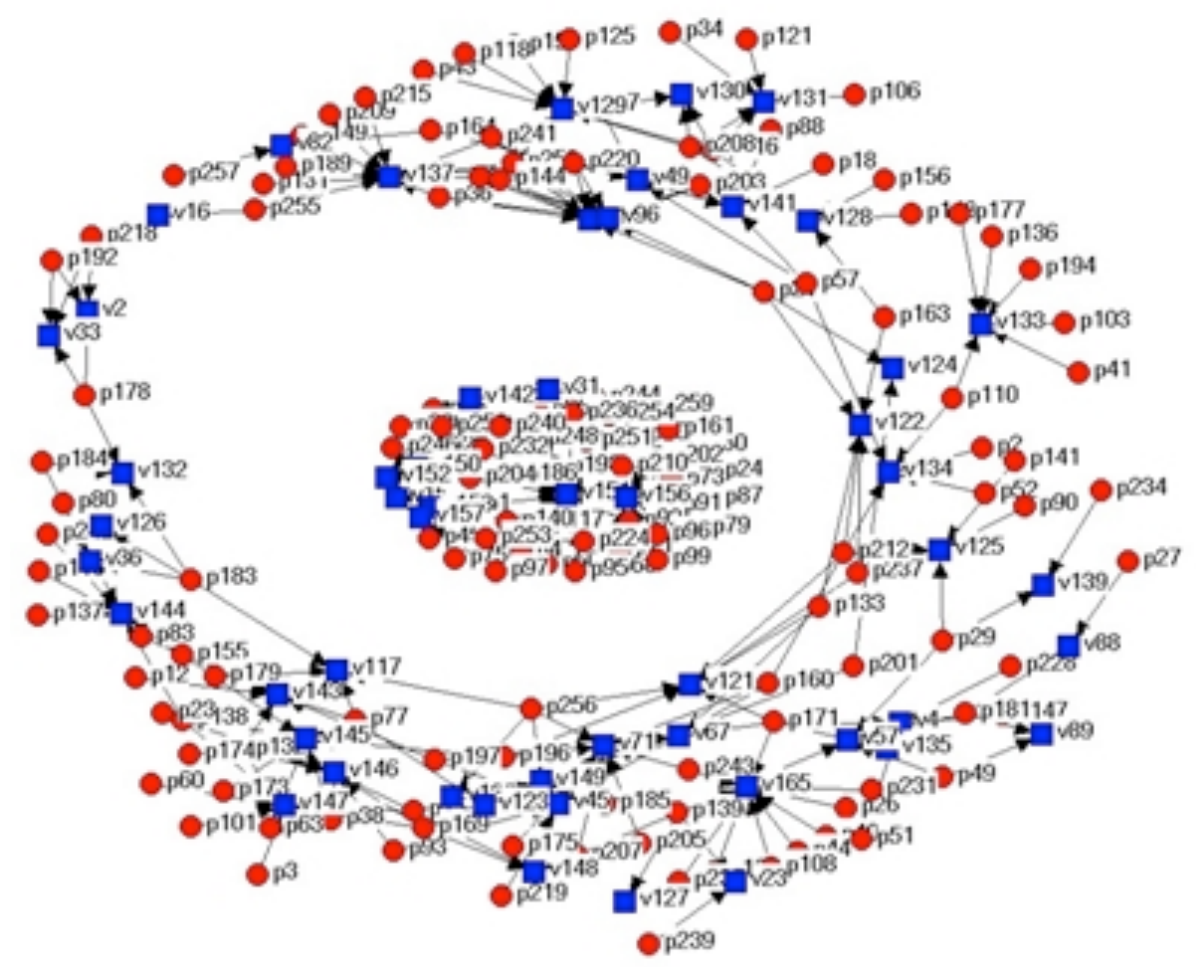

Frequent Idea Interaction Network

Figure 7: Knowledge-building sub-networks. In all figures, unit of analysis is "contribution," in which each red-circled-node represents a participant; each blue-squared-node represents a view; and each tie represents a note contribution by a participant to a view.

Table 7 summarizes statistics about the four sub-networks. The Sustained Knowledge Innovation Network as a sub-network has the highest number of note contribution and ties between participants and views and represents a more dynamic network for Knowledge Building. The Emerging Network as a sub-network shows the lowest numbers of note contribution and ties and the highest numbers of inactive participants and views; it is clear that its weakness lies in its low participation. The Intensive Participant Interaction Network as a subnetwork has a lower number of active participants and a higher number of active views whereas the Frequent Idea Interaction Network as a sub-network has a higher number of active participants and a lower number of active views. These results suggest an imbalance between participant and idea interaction for the latter two sub-networks. Such disequilibrium is reflected in: (1) strong participation within certain Knowledge Forum views but weak exchange and diversification of ideas between views. A potential issue inherent in such a sub-network is that participants may be engaged in social interactions rather than producing and sharing ideas of value to a broader community and taking these ideas to greater depth; and (2) frequent exchange of ideas between Knowledge Forum views but weak participant interaction within 
these views. These network dynamics can be problematic for sustained knowledge advancement because they suggest connections between ideas across problem spaces but lack of strong participant interaction to elaborate, deepen, and improve ideas. Now that strengths and weaknesses of each sub-network in the KSN are more explicitly identified, we turn to the matter of how to enhance the design of KSN.

Table 7: Comparisons between Four Knowledge-Building Sub-Networks.

\begin{tabular}{ccccccc}
\hline Sub-networks & $\begin{array}{c}\text { Note } \\
\text { contribution }\end{array}$ & Ties & $\begin{array}{c}\text { Active } \\
\text { participants }\end{array}$ & $\begin{array}{c}\text { Active } \\
\text { views }\end{array}$ & $\begin{array}{c}\text { Inactive } \\
\text { participants }\end{array}$ & $\begin{array}{c}\text { Inactive } \\
\text { views }\end{array}$ \\
\hline Emerging Network & $(421)$ & $(136)$ & 93 & $(50)$ & 108 & 62 \\
$\begin{array}{c}\text { Frequent Idea } \\
\text { Interaction Network }\end{array}$ & 659 & 241 & 141 & 54 & 57 & 6 \\
$\begin{array}{l}\text { Intensive Participant } \\
\text { Interaction Network }\end{array}$ & 1411 & 346 & $(39)$ & 109 & 19 & 3 \\
$\begin{array}{c}\text { Sustained Knowledge } \\
\text { Innovation Network }\end{array}$ & $\mathbf{2 6 9 5}$ & $\mathbf{7 7 5}$ & 57 & 60 & $(1)$ & $(0)$ \\
\hline
\end{tabular}

Note: Note contribution is the total number of notes contributed to a given sub-network; Ties are the total connections between participants and views in a given sub-network; Active participants are participants who contribute at least one note to a given sub-network; Active views are views that receive at least one note contribution in a given sub-network; Inactive participants contribute no notes; inactive views have no participants contributing notes to them. Bolded numbers refer to the highest value; numbers in parenthesis refer to the lowest value.

\section{Expanding the Possibilities}

This research represents a design experiment and its main purpose is to improve network dynamics within the KSN. To this end, we (1) examined KSN's network growth over four years; (2) analyzed network dynamics; and (3) identified potential strengths and weaknesses relevant to participant and idea interaction. The goal was to identify design improvements to enhance sustained knowledge advancement within the KSN. In summary, the KSN's growth and sustainability over time, as revealed through our analyses, suggests the possibility of achieving increasingly high levels of knowledge advancement. Analysis of KSN's interaction patterns suggests two possible means to improve the KSN. The first is to enhance participant interaction between isolated sub-communities in the periphery, and the second is to increase idea connections between more temporally distant Knowledge Forum views (e.g., views created in Year 1 and views created in Year 4). While KSN is moving toward a sustained knowledge innovation network with strong participant interaction and strong idea interaction, there remain a fair number of reasonably inactive participants $(\underline{n}=108)$ and views $(\underline{n}=62)$ whose connections can be further enhanced. 
An important challenge is thus to establish more dynamic, direct, and concurrent connections between participants and ideas of the four types of sub-networks identified above, as this is likely to enhance Knowledge Building. For example, literature has suggested that less active participants or peripheral members in a community can lead to strength (Granovetter, 1983). Sometimes, less active participants in one network/discipline may be active core members in another network/discipline. They represent a potential source of fresh and diversified ideas; they may be able to bring in new ideas from different disciplines, if their ideas can be more directly linked. Other times, less active participants may be practitioners (e.g., educational or health care practitioners) whose ideas may be of great value in terms of their practical implications to theorists or researchers if more direct discourse connections can be provided. Or, less active participants may be simply peripheral participants in a community. So, establishing more direct connections may be helpful in bringing these peripheral participants (Wenger, 1998) into the culture of core members. Low or imbalanced participant and idea interaction may also have to do with KSN's increasing network size. While continual growth in the KSN is desirable, it also increases the difficulty of maintaining dynamic and effective participant and idea interactions for continual knowledge advancement.

To address the above challenges and issues it is important to support more direct and meaningful connections, and perhaps a mechanism to identify who the less active participants are (e.g., whether they are practitioners or new members) and how to engage them.

Our research team is currently adding new design features into Knowledge Forum, including the development of a suite of new assessment tools (Hong, Scardamalia, Messina \& Teo, 2008; Scardamalia, Bransford, Kozma \& Quallmez, 2010). One of the new tools is a more powerful Social Network Analysis Tool, which enables members to freely explore existing interaction patterns among participants in the KSN (cf. Hoadley \& Pea, 2002; Vivacqua, Moreno \& de Souza, 2003). Another tool is the Semantic Analysis Tool (Hong \& Scardamalia, 2008; Teplovs, 2005), which allows members to explore idea interaction patterns between views (e.g., what ideas relate to what ideas). Tools for identifying promising ideas should also help bring ideas to the attention of all participants, regardless of whether they were generated by the periphery or core group. At an individual level, the tools are designed to extend members' social metacognitive capacity (e.g., knowledge of others' knowledge, see Hong \& Lin, 2008) to support epistemic agency (Russell, 2002; Scardamalia, 2002) for more effective Knowledge Building initiated by the members themselves. A newly created KSN view is being used to elaborate new tools for meta-discourse and "big ideas." This will allow more productive interaction based on ideas rising to a higher plane across views. These new tools should allow members to monitor and reflect more often on who has worked on which ideas (or sets of ideas), so members share a meta-perspective on their work. More effectively distributed Knowledge Building processes should result (Hewitt \& Scardamalia, 1998).

As Scardamalia (2003a) suggests, "Networks are ubiquitous, but the social engineering of networks for effective action is in its infancy" (p.63). The importance of this study lies in its possible contribution of new knowledge to our understanding of social processes and of how such processes can be enhanced to create a more dynamic, inclusive, and sustained network 
for knowledge advancement. Specifically, this study expands understanding of the strengths and weaknesses of four possible network models and of how these models can be mapped onto the structure of the KSN to increase self-organizing innovation dynamics (Rycroft, 2003).

Our society is increasingly organized around networks. Having the know-how and capacity to design more innovative networks for a more creative knowledge society has become increasingly important (Gloor, 2006). To address this societal concern, our study provides an initial, overall look at four different network models, and used these models as an analytical tool to examine the network structure of the KSN. For future research, it should be fruitful to further explore the social dynamics within each specific network model, compare network models, and investigate how a network model evolves over time. Doing so would help to explain the complex network phenomena in the KSN and to continually improve its design to support sustained Knowledge Building.

\section{Acknowledgments}

This research was funded by an Initiative on the New Economy (INE) Grant from the Social Sciences and Humanities Research Council of Canada (512-2002-1016). We owe special thanks to all participants for their contributions to the Knowledge Society Network.

\section{References}

Bereiter, C. (2002). Education and mind in the knowledge age. Mahwah, NJ: Lawrence Erlbaum Associates.

Bereiter, C., \& Scardamalia, M. (1996). Rethinking learning. In D. R. Olson \& N. Torrance (Eds.), The handbook of education and human development: New models of learning, teaching and schooling (pp. 485-513). Cambridge, MA: Basil Blackwell.

Bereiter, C., \& Scardamalia, M. (2010). Can children really create knowledge? Canadian Journal of Learning and Technology, 36(1).

Bielaczyc, K., \& Collins, A. (2006). Fostering knowledge-creating communities. In A. M. O'Donnell, C. E. Hmelo-Silver \& G. Erkens (Eds.), Collaborative learning, reasoning, and technology (pp. 37-60). Mahwah, NJ: Lawrence Erlbaum Associates.

Borgatti, S. P., \& Everett, M. G. (1999). Models of core/periphery structures. Social Networks, 21, 375-395.

Borgatti, S.P., Everett, M.G., \& Freeman, L.C. (2002). Ucinet 6 for Windows. Harvard: Analytic Technologies.

Brown, J. S., \& Duguid, P. (2000). The social life of information. Boston, MA: Harvard Business School Press.

Burtis, J. (1998). Analytic Toolkit for Knowledge Forum. Centre for Applied Cognitive Science: The Ontario Institute for Studies in Education/University of Toronto.

Knowledge Society Network: Toward a Dynamic, Sustained

Network for Building Knowledge 
Chubin, D. E. (1976). The conceptualization of scientific specialties. The Sociological Quarterly, $17,448-476$.

Dennett, D. (1995). Darwin's Dangerous Idea. New York, NJ: Simon \& Schuster.

Drucker, P. (1968). The age of discontinuity: Guidelines to our changing society. New York: Harper \& Row.

Evans, P., \& Wolf, B. (2005). Collaboration rules. Harvard Business Review, 83(7), 96-104.

Freeman, L. C. (1979). Centrality in social networks: Conceptual clarification. Social Networks, 1, 215-239.

Fuchs, C. (2005). The Internet as a self-organizing socio-technological system. Cybernetics \& Human Knowing, 12(3), 37-81.

Gloor, P. A. (2006). Swarm creativity: Competitive advantage through collaborative innovative networks. New York: Oxford University Press.

Granovetter, M. (1983). The strength of weak ties: A network theory revisited. Sociological Theory, 1, 201-233.

Hewitt, J., \& Scardamalia, M. (1998). Design principles for distributed Knowledge Building processes. Educational Psychology Review, 10(1), 75-96.

Hoadley, C. M., \& Pea, R. D. (2002). Finding the ties that bind: Tools in support of a knowledgebuilding community. In K. A. Renninger \& W. Shumar (Eds.), Building virtual communities: Learning and change in cyberspace (pp. 321-354). New York: Cambridge University Press.

Homer-Dixon T. (2000). The ingenuity gap. New York, NY: Random House.

Homer-Dixon, T. (2006). The upside of down: Catastrophe, creativity and the renewal of civilization. London: Island Press.

Hong, H.-Y., \& Lin, X. D. (2008). Introducing people knowledge into science learning. In G. Kanselaar, V. Jonker, P.A. Kirschner, \& F.J. Prins (Eds.), International Perspectives in the Learning Sciences: Cresing a learning world. Proceedings of the Eighth International Conference for the Learning Sciences - ICLS 2008, Vol. 1 (pp. 366-373). Utrecht, the Netherlands: International Society of the Learning Sciences, Inc.

Hong, H.-Y., \& Scardamalia, M. (2008). Using key terms to assess community knowledge. Paper presented at the annual conference of American Educational Research Association (AERA), New York.

Knowledge Society Network: Toward a Dynamic, Sustained 
Hong, H.-Y., Scardamalia, M., Messina, R., \& Teo, C. L. (2008). Principle-based design to foster adaptive use of technology for building community knowledge. In G. Kanselaar, V. Jonker, P.A. Kirschner, \& F.J. Prins (Eds.), International Perspectives in the Learning Sciences: Cresing a learning world. Proceedings of the Eighth International Conference for the Learning Sciences - ICLS 2008, Vol. 1 (pp. 374-381). Utrecht, the Netherlands: International Society of the Learning Sciences, Inc.

Hong, H.-Y., \& Sullivan, F. R. (2009). Towards an idea-centered, principle-based design approach to support learning as knowledge creation. Educational Technology Research \& Development, 57(5), 613-627.

Kling, S., \& Rosenberg, N. (1986). An overview of innovation. In R. Landau \& N. Rosenberg (Eds.), The positive sum strategy: Harnessing technology for economic growth (pp. 275-305). Washington, DC: National Academy Press.

Laferrière, T., Montané, M., Gros, B., Alvarez, I., Bernaus, M., Breuleux, A., ... Lamon, M. (2010). Partnership for Knowledge Building: An emerging model. Canadian Journal of Learning and Technology, 36(1).

Lave, J., \& Wenger, E. (1989). Situated learning: Legitimate peripheral participation. Cambridge, UK: Cambridge University Press.

Newman, M. E. J. (2003). The structure and function of complex networks. SIAM Review, 45(2), 167-256.

Nonaka, I., \& Takeuchi, H. (1995). The knowledge-creating company. New York, NY: Oxford University Press, Inc.

Pestre, D. (2003). Regimes of knowledge production in society: Towards a more political and social reading. Minerva, 41, 245-261.

Philip, D. N. (2010). Social network analysis to examine interaction patterns in knowledgebuilding communities. Canadian Journal of Learning and Technology, 36(1).

Polanyi, M. (1967). The tacit dimension. New York: Anchor Books.

Prehofer, C., \& Bettstetter, C. (2005). Self-organization in communication network: Principles and design paradigms. IEEE Communications magazine, 43(7), 78-85.

Russell, A. (2002). The role of epistemic agency and Knowledge Building discourse to foster interprofessional practice in a Canadian hospital. Paper presented at the American Educational Research Association, New Orleans.

Rycroft, R. (2003). Self-organizing innovation networks: Implications for globalization. Washington, DC: George Washington Center for the Study of Globalization.

Knowledge Society Network: Toward a Dynamic, Sustained Network for Building Knowledge 
Scardamalia, M. (1988, September). Sharing responsibility for advancing understanding: The role of CSILE. Invited address to the Educational Technology Center, Harvard Graduate School of Education, Cambridge, MA.

Scardamalia, M. (1999). Moving ideas to the center. In L. Harasim (Ed.), Wisdom \& wizardry: Celebrating the pioneers of online education (pp. 14-15). Vancouver, BC: Telelearning, Inc.

Scardamalia, M. (2002). Collective cognitive responsibility for the advancement of knowledge. In B. Smith (Ed.), Liberal education in a knowledge society (pp. 67-98). Chicago: Open Court.

Scardamalia, M. (2003a). Knowledge Society Network (KSN): Toward an expert society for democratizing knowledge. Journal of Distance Education, 17(3), 63-66.

Scardamalia, M. (2003b). Knowledge Building environments: Extending the limits of the possible in education and knowledge work. In A. DiStefano, K. E. Rudestam \& R. Silverman (Eds.), Encyclopedia of distributed learning (pp. 269-272). Thousand Oaks, CA: Sage Publications.

Scardamalia, M., \& Bereiter, C. (1996). Engaging students in a knowledge society. Educational Leadership, 54 (3), 6-10.

Scardamalia, M., \& Bereiter, C. (2003). Knowledge Building. In Encyclopedia of Education. (2nd ed., pp. 1370-1373). New York, NY: Macmillan Reference.

Scardamalia, M., Bereiter, C., McLean, R. S., Swallow, J., \& Woodruff, E. (1989). Computer supported intentional learning environments. Journal of Educational Computing Research, 5, 51-68.

Scardamalia, M., Bransford, J., Kozma, R., \& Quellmalz, E. (2010). New assessments and environments for Knowledge Building. Assessment and Learning of 21st Century Skills. Paper posted to http://www.atc21s.org/home/

Scardamalia, M., Hong, H.-Y., \& Zhang, J. (2006). Knowledge Society Network and knowledge innovation. . Paper presented at the annual Conference of the Society for Teaching and Learning in Higher Education (STLHE), Toronto, Canada.

Teo, C. L., Zhang, J., Hong, H.-Y., Gan, Y., \& Scardamalia, M. (2006, July). A longitudinal analysis of inquiry threads in the Knowledge Society Network. Paper presented at the 5th International Conference of the Cognitive Science (ICCS), Vancouver, Canada.

Teplovs, C. (2005). Introducing Semanta. Paper presented at the $9^{\text {th }}$ Annual Knowledge Building Summer Institute, Toronto, Canada.

UNESCO. (2005). Towards knowledge societies. New York: UNESCO Publishing.

Knowledge Society Network: Toward a Dynamic, Sustained 
Vivacqua, A., Moreno, M., \& de Souza, J. (2003). Profiling and matchmaking strategies in support of opportunistic collaboration. Paper presented at the Cooperative Information Systems, Catania, Sicily, Italy.

Wasserman, S., \& Faust, K. (1994). Social network analysis: Methods and applications. Cambridge: Cambridge University Press.

Wenger, E. (1998). Communities of practice: Learning, meaning, and identity. Cambridge, UK: Cambridge University Press.

Wickramasinghe, N. (2006). Knowledge creation: A meta-framework. International Journal of Innovation and Learning, 3(5), $558-573$.

Zhang, J. (2009). Towards a creative social Web for learners and teachers. Educational Researcher, 38, 274-279.

Zhang, J., Scardamalia, M., Lamon, M., Messina, R., \& Reeve, R. (2007). Socio-cognitive dynamics of Knowledge Building in the work of nine- and ten-year-olds. Educational Technology Research and Development, 55(2), 117-145.

Knowledge Society Network: Toward a Dynamic, Sustained 